\title{
Towards Erythropoietin Equations That Estimate Oxygen Delivery rather than Static Hemoglobin Targets
}

\author{
Charles J. Diskin \\ HNDT, Auburn University, Opelika, Ala., USA
}

\section{Key Words}

Erythropoietin - Dialysis - Renal failure - Anemia

Electrolytes $\cdot$ Physiology

\begin{abstract}
Although we have known since the 19th century that oxygen tension affects erythrocyte production, we have only recently begun to understand many subtleties of erythropoietin physiology. The unanticipated increase in mortality associated with erythropoietin use found in recent randomized studies is prompting a reassessment of static hemoglobin targets. Hemoglobin levels in dialysis patients do not correlate with endogenous erythropoietin production and may be related to differences in oxygen delivery resulting from shifts in the oxygen-hemoglobin dissociation curve. The time may have arrived to develop more physiologic targets such as oxygen delivery that would mimic the natural response to hypoxia. There are several equations that already exist that can compensate for the effects of the concentration of inorganic and organic phosphates as well as $\mathrm{pH}$, carbon dioxide, and temperature on the delivery of oxygen. However, since the shape and dispersion of the oxygen-hemoglobin dissociation curve may actually change in different disease states, more work is needed.
\end{abstract}

Copyright $\odot 2012$ S. Karger AG, Basel

\section{Introduction}

Although we have known since the 19th century that oxygen tension regulates erythrocyte production [1-3], and recent studies have shown that effect to be mediated through erythropoietin stimulated by hypoxia-inducible factor (fig. 1), we have unfortunately decided to base erythropoietin (rHuEPO) dosing upon target hemoglobin levels rather than projected oxygen delivery. Recent randomized controlled trials, however, in patients with stage 3 or 4 chronic kidney disease $[4,5]$ have found little benefit and significant complications when $\mathrm{rHuEPO}$ dosing was based upon hemoglobin targets in the normal range (13-15 g/dl) compared to patients given either placebo [6] or to patients who were given rHuEPO with lower hemoglobin target levels (10.5-11.0 g/dl). Since those results have caused a warning to be issued from the FDA [7], some have merely reduced their target hemoglobin levels to 9.0-11.0 g/dl [8] while others have called for the elimination of hemoglobin targets altogether [9]. Because endogenous erythropoietin (EPO) levels have never correlated with hemoglobin levels or transfusion requirements in dialysis patients (fig. 2) [10,11,21], elimination of hemoglobin targets altogether may not be unreasonable [12, 13]; however, there will always be the need to study the physiology and understand why EPO levels do

\section{KARGER \\ Fax +41613061234 E-Mail karger@karger.ch} www.karger.com
(C) 2012 S. Karger AG, Basel

$1660-2110 / 12 / 1201-0048 \$ 38.00 / 0$

Accessible online at:

www.karger.com/nec
Charles J. Diskin, MD

HNDT, Auburn University, BLDG No. 21

2609 Professional Drive

Opelika, AL 36801 (USA)

Tel. +1 334749 6523, E-Mail HNDT512@bellsouth.net 
not correlate [14]. Chemical perturbations of renal failure can shift the oxygen-hemoglobin dissociation curve (OHDC) to deliver varying amounts of oxygen to the tissues that results in a varying need for hemoglobin production. That need for hemoglobin production in patients with renal failure is often less than in normal subjects which should result in decreased need for erythropoietin production similar to premature infants with 'right-shifted' oxygen-hemoglobin dissociation curves (hemoglobin F less than 30\%) who defend hemoglobin levels $2-3 \mathrm{~g} / \mathrm{dl}$ lower than those in infants with 'left-shifted' curves (hemoglobin F greater than 60\%) before comparable erythropoietin responses occurred [15]. That phenomenon would then not only explain why while EPO levels do not correlate with hemoglobin levels as a whole, but also why the feedback loops in individual patients remain intact as EPO stimulation merely now occurs at lower levels of hemoglobin that varies from patient to patient [16]. Therefore shifts in the OHDC may be an extremely important factor in EPO production [17], and consideration of those shifts might be useful in $\mathrm{rHuEPO}$ dosing. Since dialysis patients living at higher geographic altitudes have higher hemoglobin levels while receiving lower doses of erythropoietin [18], which are associated with improved survival [19], this may be an appropriate time for the exploration of new more physiologic guidelines that focus upon the use of equations that would estimate rHuEPO needs based upon oxygen delivery.

\section{Relationship of Hemoglobin Structure and Sigmoidal Oxygen Dissociation Curve}

Oxygenation and deoxygenation occurs at the heme iron which is covalently linked to histadines at the eighth residue of the F helix, at residue 87 of the alpha chain and residue 92 of the beta chain. Upon deoxygenation, the hemoglobin molecule undergoes a marked change in conformation, as the beta chains rotate apart by $0.7 \mathrm{~nm}$. Deoxyhemoglobin is stabilized in a constrained or tense (T) configuration by inter- and intra-subunit salt bonds Upon the addition of oxygen, the salt bonds are sequentially broken and the fully oxygenated hemoglobin is in the relaxed (R) form. These changes in hemoglobin structure cause the characteristic sigmoidal shape of the OHDC through a phenomenon known as cooperativity where the partial saturation of hemoglobin with oxygen increases the affinity of the remaining heme. The $\mathrm{T}$ form has a relatively low affinity for oxygen since the iron at-

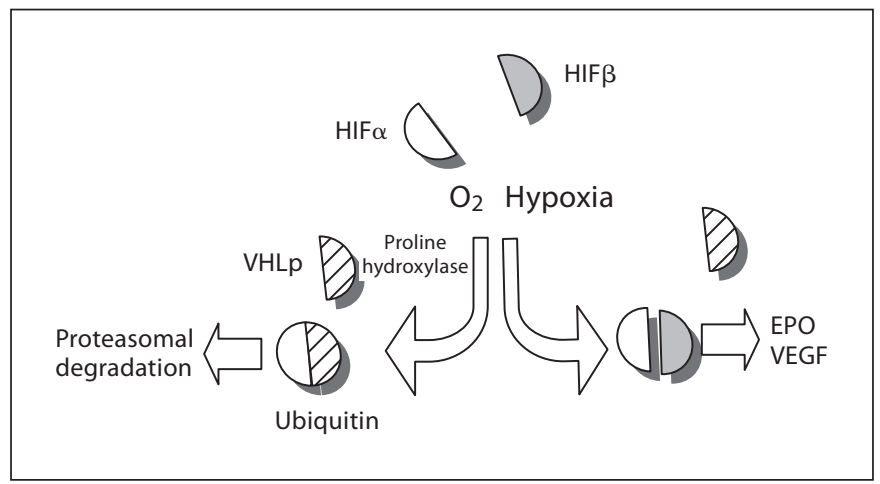

Fig. 1. In the presence of oxygen, proline residues of hypoxia-inducible factor (HIF) (white) are hydoxylated, which allows HIF binding to VHLp (striped) and subsequent ubiquitylation and proteasomal degradation. Hypoxia prevents HIF proline hydroxylation, thus, degradation. HIF is stabilized, forms the functional heterodimer with HIF $\beta$ (gray), and binds and activates hypoxia response to produce erythropoietin, vascular endothelial growth factor, glucose transporters and glycolytic enzymes. Inactive VHLp mimics hypoxia although proline hydroxylation occurs because VHLp fails to bind.

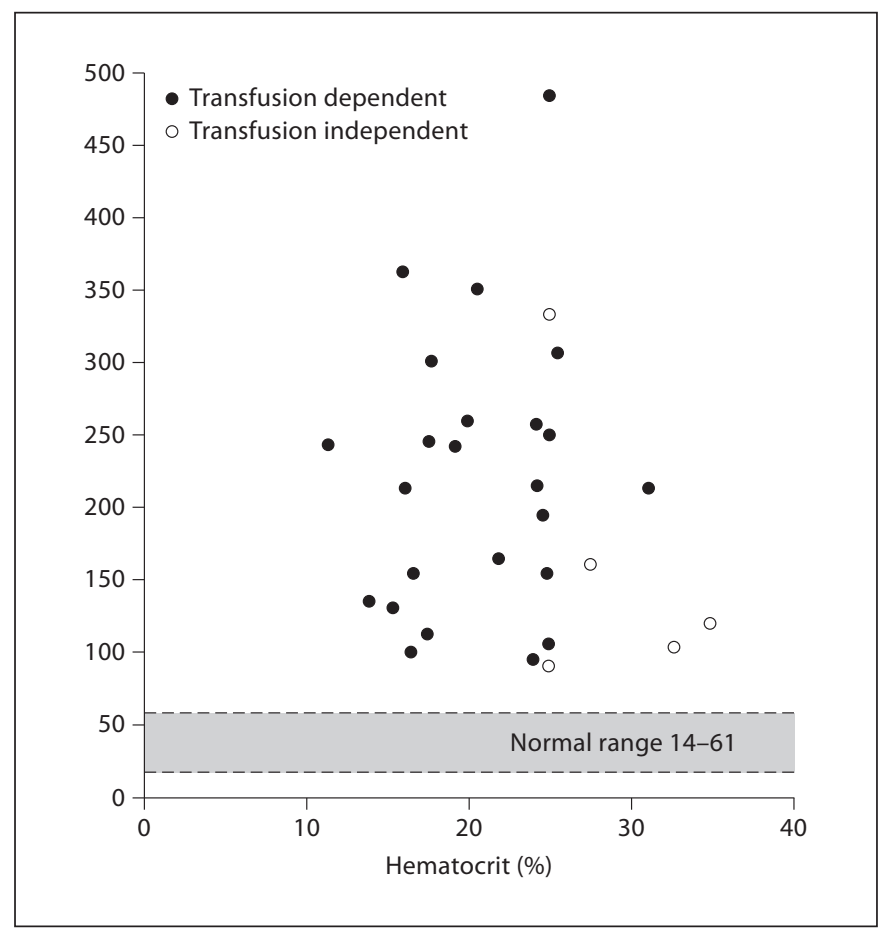

Fig. 2. Endogenous levels of erythropoietin [EP (mIU/ml)] are not related to hematocrit or transfusion dependency. 
oms lay outside the porphyrin ring by approximately $0.038 \mathrm{~nm}$, but as it flips to the R form, there is a dramatic increase in affinity as the iron is able to snap into the plane of the porphyrin ring.

Oxygen affinity is usually designated by the P50, which is the partial pressure of oxygen at which hemoglobin is $50 \%$ saturated on the OHDC. The P50 is normally $27 \mathrm{~mm} \mathrm{Hg}$ at $37^{\circ} \mathrm{C}$, and a $\mathrm{pH}$ of 7.4. However, since salt bonds that are necessary to stabilize the $\mathrm{T}$ form are destabilized by protons, acidosis is well known to shift the OHDC to the right and deliver more oxygen to the tissues/g hemoglobin, which is called the Bohr effect. Carbon dioxide reacts with the $\mathrm{N}$-terminals of alpha and beta chains to produce a similar result known as the Haldane effect. Temperature and organophosphates like 2,3-diphosphoglycerate (2,3DPG) are traditionally considered to be the only other factors that affect the position of the curve, but inorganic phosphates also induce a rightward shift that enhances tissue oxygenation. Hyperphosphatemia has long been known to be associated with increased levels of 2,3DPG which was assumed to be the cause for both the shift in the OHDC and the physiologic anemia of childhood due to increased oxygen delivery/g hemoglobin [20]. Since endogenous erythropoietin levels do not normally correlate well with hemoglobin levels in renal failure [10,21], a similar phenomenon may exist in renal failure, particularly since the erythropoietin-hemoglobin feedback loop remains intact but is just defended at lower hemoglobin levels [16, 22]. More importantly, however, was the discovery that phosphate anions themselves appear to reduce the electrostatic repulsion of charges on the B chains of hemoglobin leading to stabilization of the T form [23] and increase tissue oxygenation independent of organophosphates [24]. Similarly, the increased oxygen delivery created by phosphate anions is not affected by the carbamylation of hemoglobin in uremic patients as organic phosphate might be [25]. As a consequence equations developed to estimate the increased oxygen delivery by the acidosis and hyperphosphatemia may produce more reliable estimate of erythropoietin needs [26].

\section{Equations}

The original equations to calculate the shift of the OHDC involved only the variables of acidosis, 2,3DPG and temperature [27]:

$$
\begin{aligned}
& \log P 50=\log [26.6+0.5(M C H C-33)+0.69(D P G-14.5)] \\
& +0.0013 B E+0.48(7.4-p H)+0.24(T-37)
\end{aligned}
$$

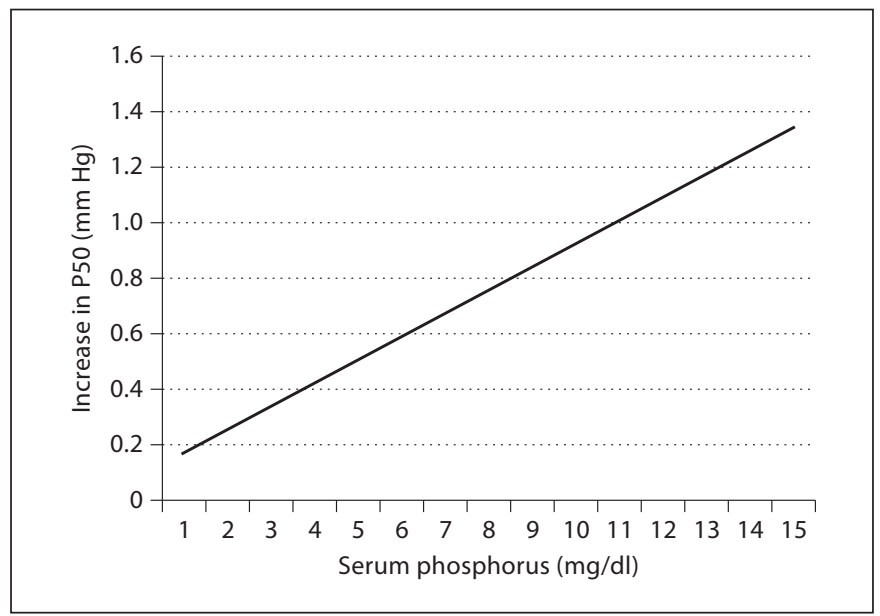

Fig. 3. Effect of serum phosphorus on the oxygen-hemoglobin dissociation curve. An increase in serum phosphorus results in an increase in hemoglobin P50. That increase can result in increased oxygen delivery as seen in figure 4.

When the normal values of $14.5 \mathrm{~mol} / \mathrm{g}$ hemoglobin for 2,3DPG and $33 \mathrm{~g} / 100 \mathrm{ml}$ for MCHC are used, the P50 at a pH of 7.4 and $37^{\circ} \mathrm{C}$ in normal blood with a base excess of zero is taken at $26.6 \mathrm{~mm} \mathrm{Hg}$ [28]. Subsequently, it has been shown that the effect of inorganic phosphates also significantly alters P50 and the following equations were developed [24]:

$$
\begin{aligned}
& \Delta P 50=-2.97 \times 10^{-3} \text { phosphate }(\mathrm{mmol} / \mathrm{l}) \\
& +0.26 \text { phosphate }(\mathrm{mmol} / \mathrm{l})-0.42 \\
& P 50=0.35 \mathrm{DPG}+0.26 \text { phosphate }(\mathrm{mmol} / \mathrm{l})+18.93 .
\end{aligned}
$$

or

Which again at standard concentrations would yield:

$P 50=5.08+0.26$ phosphate $(\mathrm{mmol} / \mathrm{l})+18.93$

or

$P 50=0.26$ phosphate $(\mathrm{mmol} / \mathrm{l})+24.01$.

As a result we can watch the change in the hemoglobin P50 over a wide range of serum phosphate values seen in hemodialysis patients (fig. 3). Furthermore, it also appears that the longer a patient has been on dialysis, the more likely his hemoglobin P50 will shift to the right through a mechanism that is not explained by traditional factors [29]. From that data the following relationship can also be generated:

$P 50=25.51+0.02$ (months on hemodialysis). 


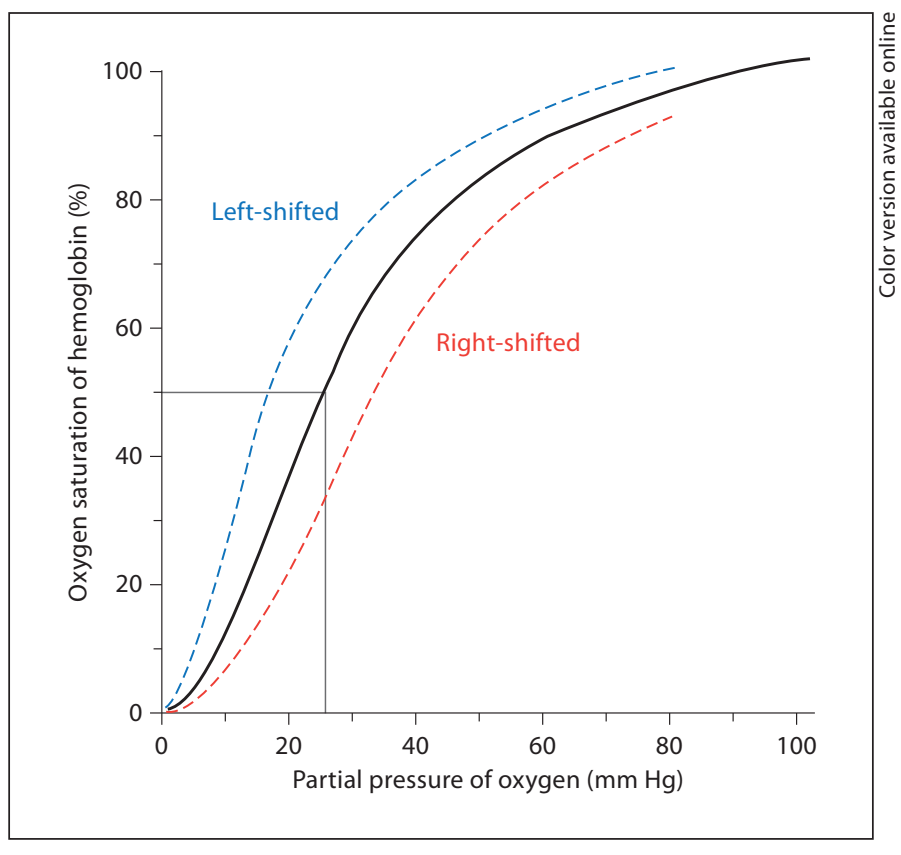

Fig. 4. Oxygen-hemoglobin dissociation curve. The solid black line is the normal curve which shows that at a $\mathrm{PO}_{2}$ of $27 \mathrm{~mm} \mathrm{Hg}$ at the tissue level, the hemoglobin would deliver only $50 \%$ of its oxygen, while with a right-shifted curve (broken line) about $70 \%$ would be delivered and a left-shifted curve would only deliver about $30 \%$. These differences could be responsible for the varying erythropoietin and hemoglobin needs.

Urea has been investigated as a factor in that phenomenon and while urea does appear to modify the binding of the available 2,3DPG [30], the effect varied and only became significant at levels higher than what is usually seen in chronic dialysis patients $(120 \mathrm{mM}$ or $336 \mathrm{mg} / \mathrm{dl}$ ).

The significance of even a small rightward shift of the P50 can be seen in figure 4 . Since the inflection point of the sigmoidal curve (where the steep slope of the curve begins) occurs at lower to mid ranges of partial pressures of oxygen, dramatic shifts in the amount of hemoglobin that remains saturated at tissue levels (about a $\mathrm{PO}_{2} 20 \mathrm{~mm}$ $\mathrm{Hg}$ ). A shift of P50 from 27 to $31 \mathrm{~mm} \mathrm{Hg}$ would result in the amount of desaturated hemoglobin increasing from just over $60 \%$ to just over $80 \%$ [31]. As a result $9 \mathrm{~g}$ of hemoglobin in the rightward shifted curve could deliver as much oxygen as $12 \mathrm{~g}$ of hemoglobin with a normal P50. Therefore, targets should be adjusted to a more physiologic basis of oxygen delivery.

Erythropoietin Equations

\section{Problems}

Unfortunately, there are some major problems associated with implementation of those equations. While urea's effect on 2,3DPG may be insignificant at commonly seen levels of BUN, it might also affect the efficacy of rHuEPO [32]. Perhaps, even more importantly, knowledge of the P50 alone may not be sufficient to determine oxygen delivery in renal failure. Traditionally, only the shape and position have been considered as factors that affect the OHDC. More recently, however, an index of dispersion of $\mathrm{PO}_{2}$ values for a given level of percent saturation has been shown to occur in disease states that are unrelated to $\mathrm{pH}$, temperature, carbon dioxide and inorganic phosphates. The maximal effect was not observed at the $\mathrm{P} 50$ but at $\mathrm{PO}_{2}$ at $20 \%$ saturation decreasing progressively to $\mathrm{PO}_{2}$ at $45 \%$ saturations. The effect is known to occur in cirrhosis [33], chronic obstructive lung disease, and patients with pancreatitis, acute respiratory distress syndrome and septic shock [34]. Therefore, equations need to be developed for the whole curve rather than just the P50 in patients with both chronic renal failure and end stage renal disease. Therefore, more studies will be needed.

\section{Conclusion}

The current algorithms for the use of rHuEPO that focus on static hemoglobin levels have been associated with increased morbidity and mortality. As a result, there has been a call for physicians to develop a more tailored and less automatic approach to the anemia of dialysis patients [35]. Unfortunately, while most physicians are quite well aware of the fact that smaller amounts of hemoglobin may be necessary in patients with renal failure to deliver the same amount of oxygen, most are unable to judge how much less hemoglobin may be needed. Although equations exist to allow the physicians to calculate how far the OHDC may be shift to the right for each individual patient once his serum phosphorus, $\mathrm{pH}, \mathrm{PCO}_{2}$, temperature, 2,3DPG and months on dialysis are known, there are still other variables that need to be explored that are peculiar to renal failure as well as simulations of dynamic physiology and changing metabolic concentrations such as in dialysis. While equations for dynamic situations have been recently created [36], they have not been tested in renal failure. In addition, there may also be a high index of dispersion in renal failure. Furthermore, no clinical studies have been performed validating the con-

Nephron Clin Pract 2012;120:c48-c53 
cept that the more physiologic focus on oxygen delivery will result in a decreased amount of morbidity and mortality. Through this minireview, I would like to generate enthusiasm for the development of two types of studies on this topic. The first type of study would define the whole OHDC in end-stage renal disease as has already been done for cirrhosis, chronic lung disease, sepsis and pancreatitis. From those equations a hemoglobin equivalence level could be programmed into the clinical laboratory analyzers that report hemoglobin levels. For any particular serum phosphorus, $\mathrm{PCO}_{2}, \mathrm{pH}, \mathrm{BUN}$ and length of time on dialysis, a corresponding equivalent hemoglobin would be generated that would represent similar oxygen delivery in a normal person who had no underlying disease at a similar altitude. For example for the three curves in figure 4 , a person with a hemoglobin of $15 \mathrm{~g}$ with the curve on the left would deliver the same amount of oxygen as a person with a hemoglobin of $9 \mathrm{~g}$ for the curve in the middle and $6.4 \mathrm{~g}$ for the curve to the right. Similar to a serum calcium that has been corrected for the serum albumin, a hemoglobin equivalence value would then give the treating physician, a more accurate estimate of physiologic availability and therefore would presumably make rHuEPO prescription decisions easier. Just as a serum calcium that has been corrected for the serum albu$\mathrm{min}$ is not as accurate as an ionized calcium level, equivalent hemoglobin levels may not be perfect, but at least they would offer a chance of improvement over the raw uncorrected data. Nevertheless, equations should then be tested in a small series of patients to determine how closely they could predict measured oxygen delivery. Like the corrected serum calcium, if they values significantly improved our estimation of oxygen delivery, finally a large scale randomized prospective clinical trial would then be needed to validate the use of such equivalence values to determine if the morbidity and mortality that has been associated with $\mathrm{rHuEPO}$ can be averted by targeting normal oxygen delivery or whether the risk is just inherent to rHuEPO use. Hopefully, we would then have enough data to begin to prescribe erythropoietin more scientifically.

\section{References}

1 Jourdanet D: De l'anemie des altitudes et de l'anemie en général dans ses rapports avec la pression de l'atmosphère. Paris, Baiilere, 1863.

2 Viault F: Sur l'augmentation considerable du nombre des globules rouges dans sang chez les habitants des haut plateaux de l'A merique du Sud. Comp R Acad d sc 1890;111:917-918.

3 Herrara AL, Lope DV: Globules rouges et densite du sang, Chapitre V, Deuxieme partie, nombre (c) in La Vie sur les haut plateaux. Washington, Smithsonian Institute, 1899.

-4 Drueke TB, Locatelli F, Clyne N, Eckardt KU, Macdougall IC, Tsakiris D, Burger HU, Scherhag A, CREATE Investigators: Normalization of hemoglobin level in patients with chronic kidney disease and anemia. N Engl J Med 2006;355:2071-2084.

5 Singh AK, Szczech L, Tang KL, Barnhart H, Sapp S, Wolfson M, Reddan D, CHOIR Investigators: Correction of anemia with epoetin alfa in chronic kidney disease. N Engl J Med 2006;355:2085-2098.

6 6 Pfeffer MA, Burdmann EA, Chen CY, Cooper ME, de Zeeuw D, Eckardt KU, Feyzi JM, Ivanovich P, Kewalramani R, Levey AS, Lewis EF, McGill JB, McMurray JJ, Parfrey P, Parving HH, Remuzzi G, Singh AK, Solomon SD, Toto R, TREAT Investigators: A trial of darbepoetin alfa in type 2 diabetes and chronic kidney disease. N Engl J Med 2009; 361:2019-2032.
7 FDA Alert. Information for healthcare pro- 15 Stockman JA 3rd, Garcia JF, Oski FA: The fessionals: erythropoiesis stimulating agents anemia of prematurity: factors governing the (ESA) [Aranesp (darbepoetin), Epogen (epo- $\quad$ erythropoietin response. N Engl J Med 1977; etin alfa), and Procrit (epoetin alfa)]. Rock- 296:647-650.

ville, $\mathrm{MD}$ : Food and Drug Administrati March 9, 2007. (Accessed May 25, 2007, at http://www.fda.gov/cder/drug/InfoSheets/ HCP/RHE2007HCP.htm.)

8 Hörl WH: What can we learn from a secondary analysis of CHOIR. Nat Rev Nephrol 2010;6:251-252.

$\checkmark 9$ Singh AK: Debate: PRO position. Am J Nephrol 2010;31:552-556.

10 Diskin CJ, Jones KLO: Erythropoietin levels in ESRD by enzyme immunoassay. Kidney Int 1985;27:160A.

11 Diskin CJ: Erythropoietin levels and androgens use: what is their relationship in the correction of anemia? Arch Intern Med 2007; 167:309.

12 Diskin CJ: Hitting the target but missing the goal? Hemoglobin targets versus oxygen delivery. Am J Kidney Dis 2007;50:344.

13 Diskin CJ: Hemoglobin targets versus oxygen delivery: is it time for a new paradigm? Blood Purif 2007;25:280.

14 Diskin CJ, Stokes TJ, Dansby LM, Radcliff L, Carter TB: Beyond anemia: the clinical impact of the physiologic effects of erythropoietin. Semin Dial 2008;21:447-454.
16 Walle AJ, Wong GY, Clemons GK, Garcia JF, Niedermayer W: Erythropoietin-hematocrit feedback circuit in the anemia of end-stage renal disease. Kidney Int 1987;31:1205-1209.

17 Ratcliffe PJ: Biology of erythropoietin. Kidney Int 1993;44:887-904

- 18 Brookhart MA, Schneeweiss S, Avorn J, Bradbury BD, Rothman KJ, Fischer M, Mehta J, Winkelmayer WC: The effect of altitude on dosing and response to erythropoietin in ESRD. J Am Soc Nephrol 2008;19:13891395.

19 Winkelmayer WC, Liu J, Brookhart MA: Altitude and all-cause mortality in incident dialysis patients. JAMA 2009;301:508-512.

20 Card RT, Brain MC: The 'anemia' of childhood: evidence for physiologic response to hyperphosphatemia. N Engl J Med 1973;288: 388-392.

21 Naets JP, Garcia JF, Tousaaint C, Buset M, Waks D: Radioimmunoassay of erythropoietin in chronic uraemia or anephric patients. Scand J Haematol 1986;37:390-394.

-22 Radtke HW, Claussner A, Erbes PM, Scheuermann EH, Schoeppe W, Koch KM: Serum erythropoietin concentration in chronic renal failure: relationship to degree of anemia and excretory renal function. Blood 1979;54:877-884. 
23 Walle AJ, Wong GY, Clemons GK, Garcia JF, Niedermayer W: Erythropoietin-hematocrit feedback circuit in the anemia of end-stage renal disease. Kidney Int 1987;31:1205-1209.

-24 Nigen AM, Manning JM, Alben JO: Oxygenlinked binding sites for inorganic anions to hemoglobin. J Biol Chem 1980;255:55255529.

-25 Clerbaux T, Detry B, Reynaert M, Kreuzer F, Frans A: Reestimation of the effects of inorganic phosphates on the equilibrium between oxygen and hemoglobin. Intensive Care Med 1992;18:222-225.

-26 Diskin C, Stokes TJ, Dansby LM, Radcliff L, Carter TB: Can acidosis and hyperphosphataemia result in increased erythropoietin dosing in haemodialysis patients? Nephrology (Carlton) 2006;11:394-399.
-27 Nigen AM, Manning JM: Interaction of anions with hemoglobin carbamylated on specific NH2-terminal residues. J Biol Chem 1975;250:8248-8250.

28 Bellingham AJ, Detter JC, Lenfant C: Regu latory mechanisms of hemoglobin affinity in acidosis and alkalosis. J Clin Invest 1971;50: 700-706.

29 Ando R, Saito H, Takeuchi J: Factors that af fect oxygen affinity of hemoglobin in chronic hemodialysis patients. Nephron 1987;46: 268-272.

30 Monti JP, Brunet PJ, Berland YF, Vanuxem DC, Vanuxem PA, Crevat AD: Opposite effects of urea on hemoglobin-oxygen affinity in anemia of chronic renal failure. Kidney Int 1995;48:827-831.

31 Severinghaus JW: Blood gas calculator. J Appl Physiol 1966 21:1108-1110.

-32 Park KD, Mun KC, Chang EJ, Park SB, Kim HC: Inhibition of erythropoietin activity by cyanate. Scand J Urol Nephrol 2004;38:6972 .
33 Clerbaux T, Detry B, Geubel B, Veriter C, Liistro G, Horsmans Y, Frans A. The oxyhemoglobin dissociation curve in liver cirrhosis. Chest 2006;129:438-445.

34 Clerbaux T, Detry B, Frans A: Plasmatic ions influence the oxyhemoglobin dissociation of patients with chronic obstructive lung disease. Pathol Biol 1996;44:259-264.

35 Hertig A, Ferrer-Marin F: Correction of anaemia on dialysis: did we forget physiology? Nephrol Dial Transplant 2011;26:11201122. Epub 2011 Mar 1.

>36 Dash RK, Bassingthwaighte JB: Erratum to: Blood $\mathrm{HbO} 2$ and $\mathrm{HbCO} 2$ dissociation curves at varied $\mathrm{O}_{2}, \mathrm{CO}_{2}, \mathrm{pH}, 2,3-\mathrm{DPG}$ and temperature levels. Ann Biomed Eng 2010; 38:1683-1701.

\section{Editorial Comment}

\section{El-Nahas, Sheffield}

The review by Diskin is a challenge to current practices in the management of anemia in CKD. We all know that the relationship between circulating erythropoietin and hemoglobin levels is variable between individuals. Furthermore, the relationship between administered rHuEpo and achieved hemoglobin is variable with increased morbidity and mortality when either doses of administered Epo are excessive or hemoglobin levels too high. Diskin argues that such inconsistencies in diagnosis and management may be the result of overlooking some basic physiological facts and the pathophysiology of anemia and oxygen delivery in CKD. Anemia in CKD is associated with changes in the OHDC that is affected by variables such as acidosis, hyperphosphatemia as well as circulating/cellular urea levels. He argues that an under- standing of these relationships between these variables and the OHDC and oxygen delivery to tissue is key to the improved and safer management of anemia in CKD. The review is a reminder to readers that simplistic therapeutic algorithms such as those currently in use for the management of anemia in CKD may cause more harm than benefit when they are not fully based on a better understanding of the pathophysiology of the underlying disease. Such understanding may become even more relevant when interventions to treat anemia of CKD are based on manipulations of hypoxia-inducible factors. Whether more complicated equations based on incorporating more modulators of anemia improve practice remains to be determined. This review is a challenge in that direction ... 